\title{
To Create Metacognitive Learning Environment: A Case Study
}

\author{
Indu Rihani \\ Principal, Rayat-Bahra College of Education Sahauran, Mohali, India
}

\begin{abstract}
Meta cognition enables individuals to manage their cognitive skills and to determine weaknesses that can be corrected by acquiring new cognitive skills. Engagement in classroom activities designed in a Meta cognitive environment allows students to link prior knowledge with new knowledge. To create Meta cognitive environment in our schools, teachers should be trained to create learner centered environment during teacher education course. Keeping this in view, a project named CHANGING TRACK in partnership with WATIS (WIPRO APPLYING THOUGHTS IN SCHOOLS) and CEVA -AN NGO, was undertaken in RAYAT AND BAHRA COLLEGE OF EDUCATION, MOHALI (PUNJAB) in which fourteen facilitators have created learning environment to create learner centered class, which empowered the students and teachers in transformational ways to positively affect the teaching learning environment, enhanced collective learning and being participatory in nature. It improved interpersonal relationships encouraged mutual trust and respect along with improvement in Cognitive skills for two hundred students for about ninety days. To prepare the facilitators twenty days programme was planned.
\end{abstract}

\section{Introduction}

The new knowledge based global society has following characteristics:

- The world's knowledge base doubles every 2-3 years

- 7000 scientific and technical articles are published each day

- Data sent from satellites orbiting the earth transmit enough data to fill 19 million volumes every two weeks;

- Graduates of secondary schools in industrialized nation have been exposed to more information than their grandparents in a life-time;

- There will be much change in the next three decades as there was in the last three centuries.
The challenge confronting our educational systems is how to transform the curriculum and teaching-learning process to provide students with the skills to function effectively in this dynamic, information - rich and continuously changing environment.

To confront this challenge, creation of Meta cognitive environment in our schools is the need of the day, and accordingly teachers should be prepared and educated to create learner centered environment during teacher education course.

To bridge the gap between the needs of schools and what is being imparted in teacher education institutes, at Rayat and Bahra College of Education, Mohali Campus INDIA a new experience was given to two hundred students. Revisiting theory and practice, learning spaces of interactive teaching were created.

\section{Need for Change}

The present globalised knowledge society is witnessing a paradigm shift from teaching content to competency; the emphasis is on continuous learning and learning how to learn. Now learning is an active inner knowledge-building process that the subject who learns carries out cognitive structure. So basic competencies which are required to be developed for learning in knowledge society are Reflective and critical capacity, Problem-solving capacity, Ability to adapt to new situations, Ability to select significant information that makes for sound decisions, Ability to continue learning in contexts of accelerated technological and socio-cultural change and permanent expansion of knowledge, Ability to seek intermediate spaces of connection between the contents of the various disciplines, Ability to enjoy reading and writing, the exercise of thought, and intellectual activity in education which promote the training of individuals whose creative interaction with information causes them to construct knowledge.

The aim of teaching today, is to promote learning through comprehension and to develop competencies. 
In every teaching-learning setting, a joint construction takes place between teacher and students that is unique and unrepeatable. Teaching is thus a process of creation and not just repetition. The student must not only acquire information but also learn cognitive strategies, that is, procedures to acquire, retrieve and use information. For this we have to shift from Teaching of certain topics to Teach with topics, and develop skills and competencies, so that our students can survive and compete in the complex environment. Under these circumstances, our teacher dominated teaching will be unable to respond to the needs of present society where knowledge is neither static nor absolute. So, education should identify situation in which learner can construct and transform knowledge and develop competencies. Hence, content is no longer seen as an end in itself, but a means to handle everyday situation.

Teaching is a profession and teacher education is a professional preparation of teachers. A teacher education curriculum must be in consonance with the requirement of school education. So teacher education needs to build capacities in the contexts and to develop the abilities to discern and judge. . We can promote an educational system in which highly skilled teachers are able to generate creativity and ingenuity among their students, by experiencing creativity and flexibility themselves in how they are treated and developed as Knowledge society professionals. In their preparation, their professional development, and their working lives, today's teachers must get a grasp of, and a grip on, the knowledge society in which their students live and will Work where Teaching involves cultivating special capacities. These include developing deep cognitive learning, creativity and ingenuity among students; drawing on research, working in networks and teams and pursuing continuous professional learning as teachers; and promoting problem-solving, risk-taking, trust in fellow professionals, ability to cope with change and commitment to continuous improvement as organizations.

Teachers need to be trained in organizing learner - centered, activity based, and participatory learning experiences as well as develop higher order thinking skills. For which they should be educated to create metacognitive learning environment, because Metacognition plays a critical role in successful learning, it is important for both students and teachers Metacognition is thinking about thinking and can be used to help students learn how to learn. Activities such as planning, how to approach a given learning task, monitoring, comprehension and evaluating progress toward the completion of a task are metacognitive in nature.
In India teaching is teacher-centered and emphasis is on rote memory. But the awareness regarding the needs of knowledge society is increasing and the schools are changing towards the concept of creating a conducive learning environment.

To create such an environment, participatory approach to facilitate learning is required. Being a teacher education institution, we have taken the initiative to educate the teachers for the new situation and undertake the project-The changing tracks. Our partners in this initiatives are WATIS (Wipro Applying Thoughts in Schools) and CEVA (Centre for Education and Voluntary Action) an NGO. In session 2010-11, planning to shift the paradigm from conventional classroom to student centered interactive classroom from the session 2011-12 was done, which will enable the students to become autonomous learner and develop Higher Order Thinking Skills.

\section{Project Implemented}

CHANGING TRACKS is a three \& half month (110 days) project which we have undertaken. This case study presents the planning, implementation and evaluative phase of Changing Tracks in which participatory approach is used to uncover the strengths, weaknesses and successes. It was conducted in a college of education which has 200 students and eighteen teachers out of which fourteen have participated. The purpose of this program was to educate the teachers to use innovating ideas in their classrooms to develop higher order thinking skills The Project is completed in four Phases:

\subsection{Phase I: Planning}

Planning for paradigm shift for session 2011-12 was very thoughtfully done in session 2010-11.Faculty members were motivated and given the onus of the total activity. Many meetings were held with CEVA members and faculty members. Activities were planned on the basis of following four different kinds of abilities that learner need if they are to be effective as suggested by David Kolb

- Involve themselves fully, openly and without bias in new experiences: concrete experiences

- Reflect on and observe these experiences from many perspectives: reflective observation

- Create concepts that integrate their observations into logically sound theories: abstract conceptualization

- Use these theories to make decisions and solve problems: active experimentation

The participatory process was facilitated by Tana Paddock from Canada of 'Organization Unbound' 
together with facilitators from CEVA. http://organizationunbound.org/

\subsection{Phase I1: Educating the Facilitator}

This part examines the roles, skills, and techniques, as a facilitator, ought to consider, before initiating a training session and suggestions to create the optimal learning environment. No one can get the process right without careful preparation and practice to prepare the faculty for the new role, a faculty development workshop was organized form $18^{\text {th }}$ July to $24^{\text {th }}$ August by CEVA members for 5-6 hrs on all working days for 14 faculty members. Objectives of this workshop were

- To change the mind set of all the faculty members for their new role.

- To own the responsibility of the project-Changing Track

- The importance of energizers and how to undertake these activities

- Importance of participatory learning and creating a metacognitive environment

- To prepare learning facilitation plans for all the four compulsory subjects.

In the end of workshop, all faculty members were asked to make a team of two, keeping in mind their comfort level and interest in different subjects of B.Ed. course. Each team prepares facilitation plans for all the four compulsory subjects of the curriculum.ie:

- Philosophical and Sociological basis of Education

- Psychological basis of education

- Development of Indian Education

- Teaching learning process and School Management

\subsection{Phase III: Implementation}

Two hundred students were divided into fourteen groups, and each group assigned to one teacher. A team of two teachers combined their groups and facilitated learning for four compulsory subjects.

Working as a team has following benefits:

- During the session, a facilitator has to perform many tasks at the same time, conducting activities, assessing group mood, dealing with audio-visuals, providing guidance to group work etc. sharing the session provide opportunity to be more effective.

- It will double the creativity and experience to deal with any problem.
- By complementing each other's inputs, more emphasis on key learning points.

- Changes in style and rhythm between facilitators will keep the group more concentrated

Although working with another facilitator can have clear benefits, smooth team work was not happen automatically, conflict between facilitators will undermine the learning process. Both the facilitators should work as a team and their style and methods should be complementary to each other. Weekly Time Table is prepared. One subject is developed for one full week with the help of various activities such as by giving them presentation time, using library facility, role playing, organizing mock press conference and many such activities.

Various types of group process exercises and activities were undertaken. Some of them were as follows:

- Introduction (Ice breaking sessions )

- Energizers and group formation

- Group dynamics exercises

- Listening exercises

- Analytical exercises

Various activities relating to curriculum content and acquisition of skills, self development, rituals for building a conducive classroom culture were conducted.

\section{(i) Activities related to Content}

Examples to facilitate learning for two topics are discussed henceforth.

(a)TOPIC 1: Ceremonies and Pupil Teacher Relationship during Vedic, Buddhist and Medieval Periods

\section{Class: B.Ed \\ Time: Two hours}

Class started with the meditation session of seven minutes with the help of instrumental music. After the meditation, students were ready and fully involved in the classroom activities. Five minutes are taken for the recap of the previous day activities, three students acted dumb Charades (silent postures) and the group guessed the activities. Thereafter, facilitator asked everybody to get up and stand in a circle. Hariyali (energizer) was played for ten minutes which was enjoyed by everybody. In this, a poem "Itna Badaa pahaad,Hariyali Idhar Uhar" is recited by the facilitator and students standing in a 
circle repeat each sentence after the facilitator. Interesting part of the game is the sound modulations and the facial expressions which were changed every time it is repeated. Such an energizer gives a chance to the students to open up and act in different manners. They break their barriers and come together on a common platform to act, learn and enjoy.

After the energizer, students were asked to pick up one slip from the basket containing numbers 1,2 $\& 3$. Three groups were formed on the basis of these slips. Each group was assigned one period each i.e., Vedic period, Buddhist period and Muslim period respectively. Each group was given text handouts containing the ceremonies and Pupil teacher relationship of their respective periods. Facilitator has common instructions that each group will be going through the text and present an act of ten minutes reflecting the ceremonies and pupil teacher relationship of their periods. Preparation time of thirty minutes was given. Facilitator kept on moving from one group to another to interact with the groups and kept on asking her doubts in order to help the students think deeper into the concept and evaluate their act again and again before jumping to final conclusions. In this manner facilitator promoted Higher Order Thinking Skills among the students. After thirty minutes, each group presented their act and also discussed their text with the whole group. Queries were answered by the group members. This discussion and role play took forty five minutes.

To refresh the students Moonwalk (energizer) was done. In this all the students are asked to join hands and legs with their subsequent partners. This way they form a chain and walk jointly towards the moon, a destination pre-decided. The interesting part is that they all have to walk together and if by chance a single member looses they all have to start again and ultimately reach the moon. Being a group activity, it helps in strengthening the bonds and helps the students to accept the strengths and weaknesses of each other and work jointly for a common goal. This energizer took ten minutes.

Thereafter, the whole group sat in a common circle and facilitator asked them to think and tell 'what was the whole process they went through during the role play activity?' Students shared the activities like, we discussed, decided, gave a second thought, found a gap, thought for solution, created, evaluated, made changes and recreated. After all these responses, facilitator recollected all the responses and introduced the concept of HOTS Ladder and related various processes they have gone through with each stage of the ladder. In the end students wrote their reflections on the post in slips and pasted on the walls. In this way, the day ended with the lovely tradition of hugs.

\section{(b)TOPIC 2: Stages of Development Paper II: Development of Learner and Teaching Learning Process}

Two energizers were enacted in the start of the session that is Statues and Fruit Salad. For Statues, The teacher leads the exercise by naming an emotional state, such as nervous, or angry, or proud, etc. Students then have ten beats (each beat is about a second) to slowly move into a posture that expresses the emotional state. At the count of ten, they freeze. Teacher chooses another emotion and repeats the game. The emphasis here is on encouraging the students to move very slowly and thoughtfully, and to keep adding details to their pose.

\section{Fruit Salad}

Fruit Salad is a good game for helping students improve listening skills (such as following directions) and negotiating physical space. Arrange chairs in a circle (and equal number of chairs and players). To begin the game, assign each student a fruit: apple, pear or banana. Make sure students understand who they are ("will all the apples raise their hands? Now all the pears will raise their hands.). Teacher calls out one of the fruits: "Apple!" All the students assigned to be apples must find a new seat. Repeat with a different fruit. After sometime teacher can say "fruit salad!" Now different fruits will form a group.

\section{Content: Stages of Development in human life}

- Pre -Natal stage

- Infancy

- Childhood

- Adulthood

- Old Age

\section{Method Taken: River of Life}

The river of life was done earlier also but it was taken up again in depth this time. The students were asked to draw River of life on Colorful Charts, they shared all their life experiences followed by sharing one by one and the entire class was deeply involved in the session. Throughout the session, facilitator's attention and focus was on each student. During the sharing, the facilitators listened to everything the student had to say and did not add technical details to it at that time. The facilitator should try to let the 
session run on the trust. The students were given complete personal space, and also helped to be open as they felt that they will be heard and not judged. One of the students shared that she feels a tremendous change in herself after joining these classes. She also motivated other students by telling them that they should always give their cent percent and everything good will happen in their lives. She also said that we should be positive.

In the end, rounded up the session by relating the river of life with psychology. The facilitators tried to explain this by continually linking it with real life and this helped the students to understand the topic better, which they shared in the end.

\section{(ii)Activities related to acquisition of skills}

- Entry Point To Paradigm

- Deriving Definition

- World Café

- Visualize An Interactive Classroom Space

- Reflection

- Mapping Activity-Back To Back

- Communication

- Six Thinking Hats

- Hierarchy of Capabilities and Higher Order Thinking Skills

- Letter Writing

- MOVIE Discussion

- Parameters of Evaluation

- Self-Evaluation

\section{Description of the Activities Entry Point to Paradigm: Forced Debate Time: 1 hour Objectives:}

- To help the participants question their beliefs and reason them

- To help the participants analyze deeply the merits and demerits of both types of classrooms irrespective

The participants were divided into two groups. One group was asked to talk in favor of information based classroom and another group to speak in favor of interaction based classroom.

After debate the participants found anomalies in their own theories. Many of them by the end had been exposed to new ideas. Most of them by the end believed that interaction based learning was a better way where as some believed that a classroom should be an amalgamation of interaction and information based learning.

\section{(ii) Activity For Self Development}

Exploring and knowing one's own self is one of the most important things for any human. We include a lot of experiences that give participants an opportunity to connect with themselves in our programs. We believe that a person who knows her strengths, weaknesses, where she/he is coming from (intellectually/emotionally/ideologically) and is aware of her emotions can prove to be a more effective facilitator. A person who has had a chance to explore different behavior options and choices is emotionally stronger and would be able to connect meaningfully with her students. In fact, the choices a facilitator makes and so the learning quotient of her learners could depend on this factor.

\section{List of the Activities}

- High Five Meditation

- The River of Life

- Tree of Life

- The Happiness Mind Map

\section{Description of the Activities High five meditation Time: 15 Minutes Objectives:}

- Positive self concept

- Discarding negative patterns

- Positivity in the workplace

This activity was done in pairs. The participants were asked to close their eyes and make a conscious effort to connect with themselves and to feel the goodness inside their own self. Then they were to let their imagination take hold and visualize themselves at their highest potential. First the person thought of what he/she could achieve, what her strengths are, what is the highest positive place she can reach and then visualized herself at that highest place. This filled her/him with tremendous positivity and them with what we call "positive-ones". After a few minutes of self visualization, the person then visualized her/his partner at her highest potential. Then the person imagined to have actually reached that potential and a most wonderful place. From this place the partners exchanged a "Hi 5".

\section{Classroom Culture}


In the teacher training workshop, the facilitators had practiced certain rituals to develop a culture and space of non-competition, love, acceptance and nonjudgement.

The rituals were:

Every day in the morning, the teachers and facilitators greeted each other with hugs. This helped in melting ice as well as starting the day with spreading positive energy and love in the space. The ritual of hugs was repeated again at the end of the day before everyone left the space.

\subsection{PHASE IV: Evaluation}

Evaluation has been done by organizing a workshop with teachers and students. A film was prepared to share the experiences by teachers and students and build their understanding about the new culture and to document the change process; teachers and some students were interviewed at length on film.

Following are the reflections regarding classroom activity shared by students:

- Friendly Environment in which freedom of thought exists

- More interaction between students and teachers

- Develops Divergent Thinking

- Confidence in public speaking

- $\quad$ Reading for understanding

- Creative expression

- Developed a sense of reasoning

- Communication skill increases

- Confidence level increases

- Everyone gets opportunity to express his/her views

- Develops creativity among individuals

- Listening to understand (and not just to answer)

- Allowing others to talk

- Comprehension

Thus it enables them to actually relate the theoretical content to their real life. With this program we are able to integrate personality development and communication skill activities with main curriculum. It also helps to enhance self esteem and share their feelings as well as encourage them to work in a team. Good facilitation leads to good group feeling and empathy between participants. As a facilitator, one has to guide for self reflection and give feedback immediately for which feedback check list is provided to all facilitators.

Main challenges in conducting this program were-Resistance to change by faculty and students, concern of students to cover the course content, adjustment of timetable, more workload to teachers and new role of faculty. Students feel that they are engaged in child like activities. Their more concern was regarding evaluation process adopted by university and to give appropriate weight age to all components of syllabus in the timetable. With efforts and by giving the ownership of this project to faculty and students, we were successful in conducting this program. Changes in the faculty and among students were quite visible. In the month of October, our suggestion box was full of slips asking to continue with this program.

\section{Conclusions}

Participatory Approach in Teaching-Learning Process is very useful for children of all age groups and adults and its use is welcomed by all. It helps us to sustain a culture of higher order thinking in an education institution. Engagement in classroom activities designed in a Meta cognitive environment allows students to link prior knowledge with new knowledge and makes teaching learning process interesting .This approach helps in developing communication skills, expression and personality development.

\section{References}

[1] National Curriculum Framework For Teacher Education, 2009 approved by NCTE.

[2] Participatory Learning and Action: A Trainer's Guide, (1995) Jules N Pretty, IIED (International Institute for Environment \& Development) Participatory Series.

[3] Rethinking University Teaching: A conversational framework for effective use of learning technologies, Dauna Laurillard, $2^{\text {nd }}$ edition (London: Routledge Falmer, 2002).

[4] Information and Communication Technologies in Teacher Education-A Planning Guide (2002) Division of Higher Education UNESCO.

[5] http://organizationunbound.org/. (Access in April 2011).

[6] http://changingtracksrbce.blogspot.in/2011/09/learningto-changechanging-to-learn.htm 